\title{
Formal estimation of the seropositivity cut-off of the hemagglutination inhibition assay in field diagnosis of influenza $D$ virus in cattle and estimation of the associated true prevalence in Morocco
}

\author{
Claude Saegerman ${ }^{1}$ (D) | Elias Salem ${ }^{2}$ | Hicham Ait Lbacha ${ }^{3}$ | Said Alali ${ }^{3}$ | \\ Zaid Zouagui $^{3}$ | Gilles Meyer ${ }^{2}$ | Mariette F. Ducatez ${ }^{2}$ (D)
}

${ }^{1}$ Fundamental and Applied Research for Animal and Health (FARAH) Center, University of Liège, Liege, Belgium

${ }^{2}$ INRAE UMR 1225 IHAP-ENVT, Toulouse,

France

${ }^{3}$ Institut Agronomique et Vétérinaire Hassan II, Rabat, Morocco

Correspondence

Claude Saegerman, Fundamental and Applied Research for Animal and Health (FARAH) Center, University of Liège, Liege, Belgium.

Email: claude.saegerman@uliege.be

Funding information

EFSA, Grant/Award Number: GP/EFSA/ AFSCO/2017/01-GA04

\begin{abstract}
The influenza D virus (IDV) was discovered less than ten years ago. Increased interest in this virus is due to its nature (RNA virus with high mutation rate), its worldwide circulation in livestock species, its probable role in bovine respiratory disease and its zoonotic potential. Until currently, the establishment of positivity cut-off of the hemagglutination inhibition ( $\mathrm{HI}$ ) assay was not formalized in field conditions for the detection of antibodies directed against IDV in cattle (i.e. the proposed reservoir). In this study, the positivity cut-off of the $\mathrm{HI}$ assays was formally established (titre $=10$ ) using a receiver operating characteristic (ROC) curve. This information was used to estimate the sensitivity (68.04 to $73.20 \%$ ) and the specificity (94.17 to $96.12 \%$ ) of two different $\mathrm{HI}$ assays $\left(\mathrm{HI}_{1}\right.$ and $\mathrm{HI}_{2}$, with two different IDV antigens) relatively to virus micro-neutralization test (VNT) as reference test. Based on the above characteristics, the true prevalence of IDV was then estimated in Morocco using a stochastic approach. Irrespective of the $\mathrm{HI}$ assays used, the estimation of the true prevalence was statistically equivalent (between $48.44 \%$ and $48.73 \%$ ). In addition, the Spearman rank correlation between $\mathrm{HI}$ titres and VNT titres was statistically good ( 0.76 and 0.81 for $\mathrm{HA}_{1}$ and $\mathrm{HA}_{2}$, respectively). The positive (0.82 and 0.79 for $\mathrm{HA}_{1}$ and $\mathrm{HA}_{2}$, respectively) and the negative ( 0.86 and 0.85 for $\mathrm{HA}_{1}$ and $\mathrm{HA}_{2}$, respectively) agreement indices between results of $\mathrm{HI}$ assays and VNT were good and similar. This study allowed for a formal establishment of a positivity cut-off in $\mathrm{HI}$ assays for the detection of antibodies directed against IDV. This information is of prime importance to estimate the diagnostic sensitivity and specificity of the test relatively to the VNT (i.e. the reference test). Using these characteristics, the true prevalence of IDV should be determined in a country.
\end{abstract}

KEYWORDS

cattle, epidemiology, hemagglutination inhibition assay, influenza, respiratory, sensitivity, specificity, surveillance, virus 


\section{1 | INTRODUCTION}

In 2011, a new influenza D virus (IDV) was isolated from pigs with influenza-like clinical signs in Oklahoma, USA (Hause et al., 2014; Hause et al., 2013). Since then, IDV has been detected in a large host range and worldwide, i.e. IDV affected cattle, small ruminants, swine, camelids and equines in America, Europe, Asia and Africa (Dane et al., 2019; Ferguson et al., 2015; Flynn et al., 2018; Murakami et al., 2019; O'Donovan, Donohoe, Ducatez, Meyer, \& Ryan, 2019; Oliva, Eichenbaum, et al., 2019; Salem et al., 2017; Silveira et al., 2019; Snoeck et al., 2018; Trombetta et al., 2019).

The zoonotic potential of IDV is still not completely elucidated, but serological and virological studies suggested that the virus might infect human (e.g. Borkenhagen et al., 2018; Hause et al., 2013), especially exposed to cattle (White, Ma, McDaniel, Gray, \& Lednicky, 2016). Despite the absence of clinical signs, the virus replicated in the upper respiratory tract of the ferrets (a good model for studying human influenza virus) and a direct contact transmission between ferrets was observed (Hause et al., 2013). In addition, a recent study confirmed that IDV efficiently replicates in an in vitro surrogate model of the respiratory epithelium at temperatures that correspond to the human upper and lower respiratory tract (Holwerda et al., 2019). All these results suggested that human could be susceptible to IDV, but studies are still needed to confirm this hypothesis (Oliva, Mettier, et al., 2019).

Among livestock species, cattle are the most affected host, in which the virus causes moderate respiratory clinical signs alone (e.g. Salem et al., 2019; Ferguson et al., 2016), but may also play a role in the bovine respiratory complex (e.g. Salem et al., 2019; Zhang, Hill, et al., 2019; Zhang, Outlaw, et al., 2019). Consequently, cattle have been proposed as the natural reservoir of IDV (Moreno et al., 2019).

To prevent and control the worldwide spread and inter-species transmission of IDV, options can be proposed such as the development of an efficacious vaccine or the development of antiviral strategies (Asha \& Kumar, 2019). Unfortunately, due to the inherent instability and high mutation rate of influenza genomes, most current antivirals are no longer effective at inhibiting influenza virus replication (Kesinger et al., 2018) and the use of antivirus in animals is thus not advised. However, there are some encouraging developments in the field of vaccination. An inactivated influenza $D$ virus vaccine partially protected cattle from respiratory disease caused by homologous challenge (Hause et al., 2017). In another study, a DNA vaccine encoding the consensus hemagglutinin-esterase fusion (HEF) protein of two lineages of IDV (D/OK and D/660) was designed and its efficacy was tested in a guinea pig model. This consensus DNA vaccine elicited high-titre neutralizing antibodies and achieved sterilizing protection against two lineage-representative IDV intranasal infections (Wan et al., 2018; Yu et al., 2017).

The direct diagnosis of the IDV is based mainly on isolation of the virus (e.g. Ferguson et al., 2015) and real-time polymerase chain reaction (PCR) methods (e.g. Faccini et al., 2017). These methods contributed to the understanding of the molecular epidemiology of IDV. The indirect diagnosis of IDV aims at measuring serum antibody to IDV, with mainly virus neutralization (VNT) and hemagglutination inhibition (HI) assays (Moreno et al., 2019). Although there are valuable serologic methods, VNT requires live IDV, well-trained staff and time (Gauger \& Vincent, 2020). In addition, a monoclonal antibody-based competitive ELISA test was developed recently and validated for the detection of antibodies against IDV (Moreno et al., 2019). However, in the absence of a commercial ELISA test, the hemagglutination inhibition assay is still often used to estimate the apparent prevalence of the disease. However, the positivity cut-off value of this test had not been formally established.

Further studies are needed to better understand the role of IDV in respiratory infections, especially in cattle, and to evaluate the costbenefit ratio of mitigation measures (control and prevention) (Oliva, Salem, Meyer, \& Ducatez, 2018). To estimate the cost of IDV, the true prevalence of the disease should be assessed. This true prevalence (at population level) can be estimated based on the apparent prevalence using available serological test for which the characteristics must be properly known (sensitivity and specificity) (Rogan \& Gladen, 1978).

The first aim of this study was to properly assess the positivity cut-off of $\mathrm{HI}$ assays with two distinct antigens relatively to VNT as the gold standard test and using a receiver operating characteristic (ROC) curve, and subsequently, the characteristics of sensitivity and specificity of these assays in the cattle population (i.e. the proposed natural reservoir) and a dataset from Salem et al., 2017. Secondly, the true prevalence was estimated in Morocco based on both the estimation of the characteristics of $\mathrm{HI}$ assays and the apparent prevalence.

\section{2 | MATERIALS AND METHODS}

\section{1 | Data selection}

Morocco has 3.2 million head of cattle. A total of 200 cattle sera were sampled between 2012 and 2015, in different geographical areas of Morocco (Table 1, Salem et al., 2017). This sample size was determined using the population size (see above), an expected IDV animal prevalence of $25 \%$, with an accepted error of $6 \%$ and a confidence level of $95 \%$, that is, 201 samples (rounded to 200 ).

\section{2 | Laboratory analyses}

Hemagglutination inhibition assay and virus micro-neutralization test (VNT) were performed as described previously (Salem et al., 2017).

\subsubsection{Hemagglutination inhibition (HI) assay}

The sera were all treated with receptor destroying enzyme (RDE) (Seika) and heme adsorbed on packed horse red blood cells. Four hemagglutination units of D/bovine/Nebraska/9-5/2012 kindly provided by $\mathrm{Dr}$. Ben Hause and subsequently named $\mathrm{HI}_{1}$ or D/ bovine/France/5920/2014 and subsequently named $\mathrm{HI}_{2}$ and $1 \%$ 
TAB LE 1 Origin ${ }^{a}$ of Moroccan bovines sampled during years 2012-2015

\begin{tabular}{|lc|}
\hline Region & Number of sera \\
\hline Souss-Massa & 15 \\
\hline Gharb & 22 \\
\hline Zemour-Zair & 31 \\
\hline Tadla-Beni Mellal & 21 \\
\hline Middle Atlas & 25 \\
\hline Saïss & 6 \\
\hline Haouz & 16 \\
\hline Oriental & 5 \\
\hline Chaouia & 43 \\
\hline High Rif & 12 \\
\hline Oriental High Atlas & 4 \\
\hline Total & 200 \\
\hline
\end{tabular}

${ }^{a}$ Geographic (bioclimatic) areas with specific husbandry practices

horse red blood cell were used for HI assays. As IDV harbours hemagglutinin-esterase fusion proteins on its surface, which hemagglutinate in presence of red blood cells of chicken, turkey or horse origin, the $\mathrm{HI}$ test can be used for IDV antibodies detection.

\subsection{2 | Virus micro-neutralization test}

The VNT was carried out on swine testis cells (ATCC), using 100 tissue culture infectious doses 50 per well (D/bovine/France/5920/2014) and 5 days' incubation at $37^{\circ} \mathrm{C}$ and $5 \% \mathrm{CO} 2$ without TPCK trypsin and an hemagglutination assay as a readout (with $1 \%$ red blood cells). We use D/bovine/France/5920/2014 that grows to higher titres on cells than D/bovine/Nebraska/9-5/2012 in our laboratory conditions.

VNT titres tested were <10, 20, 30, 40, 60, 80, 160, 320, 640 and 1,280 . VNT titres were considered positive when $\geq 10$. For future statistical analyses, a titre $<10$ was assimilated as 5 (middle bound value).

Positive IDV reference serum was produced in house by inoculating rabbits subcutaneously with purified D/bovine/ Nebraska/9-2/2012. We also used IDV positive French cattle serum (from an experimental infection).

As no negative IDV reference serum was available (specific pathogen free calves do not exist), we used some sera from few cohorts as negative controls, both from the field and uninfected controls from experimental infections (Oliva, Eichenbaum, et al., 2019; Salem et al., 2017, 2019).

\section{3 | Statistical analyses}

\subsection{1 | Receiver operating characteristic (ROC) curve}

The receiver operating characteristic (ROC) curve was used to determine the best cut-off of $\mathrm{HI}_{1}$ and $\mathrm{HI}_{2}$ related to the $\mathrm{VNT}$ as reference.
The ROC is a probability curve. The ROC curve was plotted with true positive results ( $\mathrm{Y}$-axis) against the false positive results (X-axis). The area under the ROC curve (AUC) is the performance measurement for the classification test at various threshold settings. The higher the AUC, the better the test is able to distinguish between infected and healthy cattle (i.e. measure of the separation of the two subpopulations). In addition, Youden's index ' $\mathrm{J}$ ' is frequently used in conjunction with the ROC curve analysis, with:

Youden $/$ s index $=$ sensitivity + specificity -1

Its value ranges from 0 through 1 (inclusive). A zero value is observed when a diagnostic test gives the same proportion of positive results for groups with and without the disease. A value of 1 indicates that there are no false positives or false negatives, i.e. the test is perfect. In a ROC curve, the calculation of Youden's index in all points allows to determine the best cut-off of the test (i.e. optimal Youden's index).

\subsubsection{Estimation of the relative sensitivity, specificity of the hemagglutination inhibition assays and the true prevalence}

The sensitivity and the specificity of the $\mathrm{HI}$ assays were estimated based on the cut-off established using the ROC curve and relatively on the results of the VNT as reference test. The $95 \%$ confidence interval of each parameter was estimated based on exact binomial distribution, using STATA/SE 14.2 (StataCorp.).

The animal true prevalence (TP) of IDV was estimated from the apparent prevalence (AP) calculated in this study using $\mathrm{HI}$ assays (i.e. the seroprevalence) and the individual diagnostic specificity (Sp) and sensitivity (Se) based on the ROC curve, using the Rogan and Gladen formula (1978):

$$
\mathrm{TP}=(\mathrm{AP}+\mathrm{Sp}-1) /(\mathrm{Se}+\mathrm{Sp}-1)
$$

For the AP, Sp and Se values of different $\mathrm{HI}$ assays, a uniform variable was used, taking into account the extreme values of the $95 \%$ confidence interval, and a stochastic modelling (1,000 Monte Carlo simulations) was performed using @Risk 7.5.2 software (Palisade Corporation, Ithaca, New York, USA) to estimate the TP with a $95 \% \mathrm{Cl}$ using Equation (2).

\subsection{3 | Agreement between hemagglutination inhibition assays and virus micro-neutralization test}

The correlation between the titres of $\mathrm{HI}$ assays and the VNT was assessed using the Spearman rank correlation, a non-parametric test (Petrie \& Watson, 2013).

The two tests (positive and negative results using the cut-off selected) were compared using concordance analysis to assess their 
agreement with the results. The level of agreement was expressed in terms of Cohen kappa coefficient $(\kappa)$ (Petrie \& Watson, 2013) and of indices of positive $\left(P_{\text {pos }}\right)$ and negative agreement $\left(P_{\text {ne }}\right)$ (Cicchetti $\&$ Feinstein, 1990), the observed agreement proportion for positive and negative test results, respectively. Confidence intervals were calculated using an exact binomial distribution.

The $P_{\text {pos }}$ and $P_{\text {ne }}$ were used to resolving the paradoxes of Cohen kappa coefficient (conditions when there is a high agreement but low kappa) (Cicchetti \& Feinstein, 1990).

Using a 'two-by-two' contingency table (Table 3), the two indices of positive agreement $\left(P_{\text {pos }}\right)$ and negative agreement $\left(P_{\text {neg }}\right)$ were, respectively,

$$
P_{\text {pos }}=2 a /(2 a+b+c)
$$

and

$$
P_{\text {neg }}=2 d /(2 d+b+c)
$$

where $P_{\text {pos }}$ and $P_{\text {neg }}$ were the indices of positive and negative agreement, respectively (parameters $a, b, c$ and $d$ are detailed in Table 3).

In addition, the comparison of titres obtained in $\mathrm{HI}$ assays and VNT was assessed with a non-parametric two-sample Wilcoxon rank-sum test and using a Bonferroni correction for multiple comparisons (alpha was fixed as 0.017 , i.e. 0.05 divided by 3 comparisons).

\section{3 | RESULTS}

\section{1 | Titres of hemagglutination inhibition assays and virus micro-neutralization test}

The titres obtained for the three tests $\left(\mathrm{HI}_{1}, \mathrm{HI}_{2}\right.$ and VNT as reference) are depicted in Table 2 and Appendix S1. High titre of antibodies was observed for all the three tests. While titres of $\mathrm{HI}_{1}$ and $\mathrm{HI}_{2}$ are similar (two-sample Wilcoxon rank-sum test; $p$-value $=.51$ ), titres of VNT are significantly higher than titres of $\mathrm{HI}_{1}$ and $\mathrm{HI}_{2}$ (twosample Wilcoxon rank-sum test; $p$-value $\leq .0001$ ). Besides, according to Table 2, VNT was more sensitive than $\mathrm{HI}$ at higher titres, but less sensitive than $\mathrm{HI}$ at lower titres.

TABLE 3 Comparison of $\mathrm{HI}_{1}$ and VNT results for influenza $\mathrm{D}$ in 200 cattle samples from Morocco

\begin{tabular}{lllr} 
& & & \\
\cline { 2 - 3 } & & & \\
Positive & Negative & Total \\
Positive & $71(a)$ & $26(b)$ & 97 \\
Negative & $6(c)$ & $97(d)$ & 103 \\
Total & 77 & 123 & 200 \\
\hline
\end{tabular}

Note: (a), (b), (c) and (d) are parameters used in Equations (3) and Equation (4).
TABLE 2 Number of sera obtained in function of the assays and the titres obtained

\begin{tabular}{|rrrr|}
\hline Titre & VNT & HI $_{1}$ & HI $_{2}$ \\
\hline$<10$ & 103 & 123 & 130 \\
\hline 10 & 8 & 30 & 29 \\
\hline 20 & 13 & 15 & 15 \\
\hline 30 & 1 & & \\
\hline 40 & 21 & 22 & 9 \\
\hline 60 & 1 & & \\
\hline 80 & 16 & 6 & 8 \\
\hline 160 & 14 & 2 & 6 \\
\hline 320 & 15 & 1 & 1 \\
\hline 640 & 4 & 1 & \\
\hline 1,280 & 4 & & 2 \\
\hline
\end{tabular}

Note: $\mathrm{HI}_{1}$, hemagglutination inhibition assay using $\mathrm{D} /$ bovine/ Nebraska/9-5/2012; VNT; $\mathrm{HI}_{2}$, hemagglutination inhibition assay using D/bovine/France/5920/2014; VNT virus micro-neutralization test using D/bovine/France/5920/2014.

\subsection{Receiver operating characteristic (ROC) curve}

The best cut-off for $\mathrm{HI}_{1}$ or $\mathrm{HI}_{2}$ was estimated based on the VNT as reference test and using a ROC curve (Figure 1). For the two ROC curves, the best positivity cut-off was the same, with a titre $=10$. At this point estimate, the optimal Youden's indexes were observed and reached 0.67 and 0.64 for $\mathrm{HI}_{1}$ and $\mathrm{HI}_{2}$, respectively.

The area under the ROC curve (AUC) for $\mathrm{HI}_{1}$ and $\mathrm{HA}_{2}$ was, respectively, 0.84 (standard error $=0.026$ ) and 0.83 (standard error $=0.025$ ). The difference between these areas was not significant $\left(\chi^{2}=0.34 ; p\right.$-value $\left.=.56\right)$.

\subsection{Estimation of the sensibility and specificity of hemagglutination inhibition assays relative to the micro-neutralization as reference test}

Based on the cut-off determined by the ROC curve for $\mathrm{HI}_{1}$ and $\mathrm{HI}_{2}$, the contingency tables were established for $\mathrm{HI}_{1}$ and $\mathrm{HI}_{2}$, respectively (Tables 3 and 4).

The sensitivity and the specificity of the $\mathrm{HI}_{1}$ related to the VNT were $73.20 \%$ (95\% Cl: 63.24-81.68) and 94.17 (95\% Cl: 87.75-97.83), respectively. Youden's index for $\mathrm{HI}_{1}$ was 0.67 .

The sensitivity and the specificity of the $\mathrm{HI}_{2}$ related to the VNT were 68.04\% (95\% Cl: 57.80-77.15) and 96.12 (95\% Cl: 90.35-98.93), respectively. Youden's index for $\mathrm{HI}_{1}$ was 0.64 .

\subsection{Estimation of the apparent and true prevalence}

The apparent prevalence of IDV was estimated with $\mathrm{HI}_{1}$ and $\mathrm{HI}_{2}$, as, respectively, $38.50 \%(95 \% \mathrm{Cl}: 31.72-45.62)$ and $35.00 \%$ (95\% Cl: 28.41-42.05). There was no statistical difference in the 


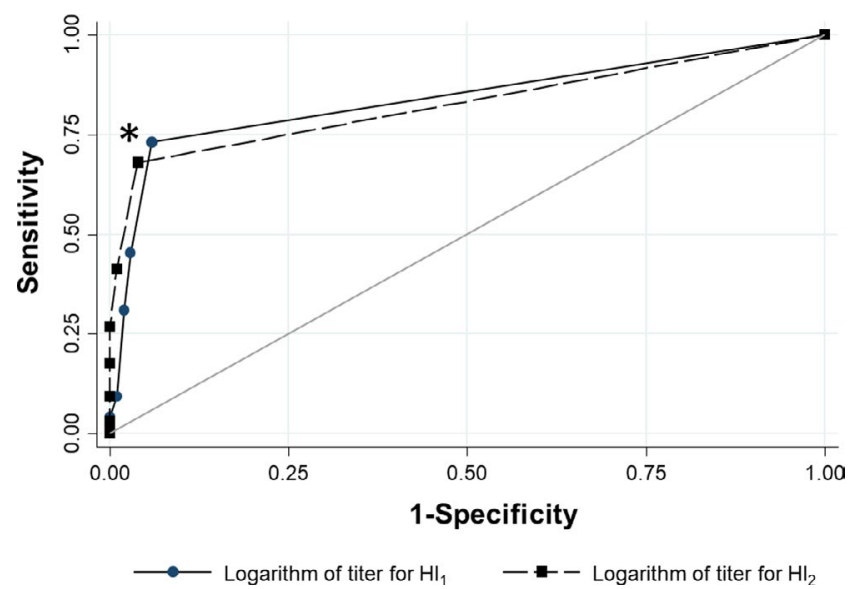

FIGURE 1 Receiver operating characteristic (ROC) curve based on hemagglutination inhibition assays and virus microneutralization test as reference. $\mathrm{HI}_{1}$, hemagglutination inhibition assay using D/bovine/Nebraska/9-5/2012; VNT; $\mathrm{HI}_{2}$, hemagglutination inhibition assay using D/bovine/ France/5920/2014; the reference test was the virus microneutralization test using D/bovine/France/5920/2014. The asterisk indicates the best cut-off of the two $\mathrm{HI}$ assays (titre $=10$ )

estimation of the apparent prevalence using $\mathrm{HI}$ assays $\left(\chi^{2}{ }_{(1 \mathrm{df} ;}\right.$ 0.05) $=0.53 ; p$-value $=.47$ ).

Based on the sensitivity and the specificity of $\mathrm{HI}_{1}$ and $\mathrm{HI}_{2}$ and their above estimated apparent prevalence, the true prevalence was estimated using the Rogan and Gladen formula (1978): $48.73 \%$ (95\% Cl: 34.06-64.40) with $\mathrm{HI}_{1}$ and 48.44\% (95\% Cl: 33.69-65.14) with $\mathrm{HI}_{2}$ (Figure 2). These two estimations were concordant $\left(\chi^{2}{ }_{(1 \mathrm{df} ;}\right.$ $0.05)=0.1$ ( $p$-value $=.92)$.

\subsection{Level of agreement between tests}

The Spearman rank correlation between the logarithm of the titre of $\mathrm{HI}_{1}$ and the logarithm of the titre of VNT was 0.76 ( $p$-value <.0001). The Spearman rank correlation between the logarithm of the titre of $\mathrm{HI}_{2}$ and the logarithm of the titre of VNT was 0.81 ( $p$-value $<.0001$ ) (Figure 3). These correlations indicated a good relation between the titres of different tests used.

According to the cut-off of $\mathrm{HI}_{1}$ and $\mathrm{HI}_{2}$ determined previously (i.e. titre $=10$ ), the level of agreement with the results of the VNT

TAB LE 4 Comparison of $\mathrm{HI}_{2}$ and VNT results for influenza $\mathrm{D}$ in 200 cattle samples from Morocco

\begin{tabular}{lccr} 
& \multicolumn{3}{l}{$\mathrm{HI}_{2}$} \\
\cline { 2 - 4 } & Positive & Negative & Total \\
VNT & 66 & 31 & \\
Positive & 4 & 99 & 103 \\
Negative & 70 & 130 & 200 \\
\hline Total & & & \\
\hline
\end{tabular}

was calculated. The two-by-two contingency tables for two different $\mathrm{HI}$ assays are depicted in Tables 3 and 4.

These $\mathrm{HI}$ assays were in good agreement with VNT (using the scale proposed by Petrie \& Watson, 2013) as the Cohen kappa coefficient ( $\kappa)$ was of $0.68(95 \% \mathrm{Cl}$ : $0.54-0.81)(p$-value $<.05)$ and 0.65 (95\% Cl: 0.51-0.78) ( $p$-value < .05) for $\mathrm{HI}_{1}$ and $\mathrm{HI}_{2}$, respectively.

The positive agreement index (Cicchetti \& Feinstein, 1990) between $\mathrm{HI}$ assays and VNT was 0.82 (95\% Cl: 0.75-0.78) and 0.79 (95\% Cl: 0.72-0.85) for $\mathrm{HI}_{1}$ and $\mathrm{HI}_{2}$, respectively.

The negative agreement index (Cicchetti \& Feinstein, 1990) between $\mathrm{HI}$ assays and VNT was 0.86 (95\% Cl: 0.81-0.90) and 0.85 (95\% Cl: 0.80-0.89) for $\mathrm{HI}_{1}$ and $\mathrm{HI}_{2}$, respectively.

The positive and negative agreement indices were not significantly different.

\section{4 | DISCUSSION}

The interest of IDV resides in the fact that the virus was discovered recently (Hause et al., 2014; Hause et al., 2013), harbours a RNA genome with a high rate of mutations (Kesinger et al., 2018), circulates worldwide in livestock, may play a role in the bovine respiratory complex (Salem et al., 2019; Zhang, Hill, et al., 2019; Zhang, Outlaw, et al., 2019) and has a zoonotic potential (e.g. Borkenhagen et al., 2018; Hause et al., 2013; Holwerda et al., 2019).

In this study, the positivity cut-off of the $\mathrm{HI}$ assays was formally established (titre $=10$ ) for cattle in field conditions using a ROC curve. This information was used to estimate the sensitivity (between 68.04\% and 73.20\%) and the specificity (between $94.17 \%$ and $96.12 \%$ ) of $\mathrm{HI}$ assays relatively to the VNT as reference test. Based on the above characteristics, the true prevalence of the IDV was then estimated in Morocco using a stochastic approach. Irrespective of the antigen used in $\mathrm{HI}$ assays, the estimation of the true prevalence was statistically equivalent (between 48.44\% and 48.73\%). In addition, the Spearman rank correlation between $\mathrm{HI}$ and VNT titres was statistically good (0.76 and 0.81 for $\mathrm{HA}_{1}$ and $\mathrm{HA}_{2}$, respectively). The positive (0.82 and 0.79 for $H A_{1}$ and $H A_{2}$, respectively) and the negative (0.86 and 0.85 for $\mathrm{HA}_{1}$ and $\mathrm{HA}_{2}$, respectively) agreement indices between $\mathrm{HI}$ assays and VNT were good and similar. In addition, the VNT was also less sensitive than $\mathrm{HI}$ at lower titres. In humans, for influenza $\mathrm{A}$, a good correlation between $\mathrm{HI}$ and VNT titres and the lesser sensitivity than $\mathrm{HI}$ at lower titres were also previously observed (Truelove et al., 2016). Like for influenza $A$, the reason is unknown and needs more investigation (Truelove et al., 2016). Indeed, as for influenza A (Truelove et al., 2016), the use of $\mathrm{HI}$ assay for detection of antibodies against IDV is supported over the more resource intensive VNT (i.e. requires cell culture, more time and labour, and technical skill to conduct the assay compared to other serological methods) (Gauger \& Vincent, 2020).

Despite the genetic distance between the hemagglutinin-esterase fusion (HEF) genes of the two strains of IDV (Chiapponi et al., 2019), no statistical difference was observed in the 

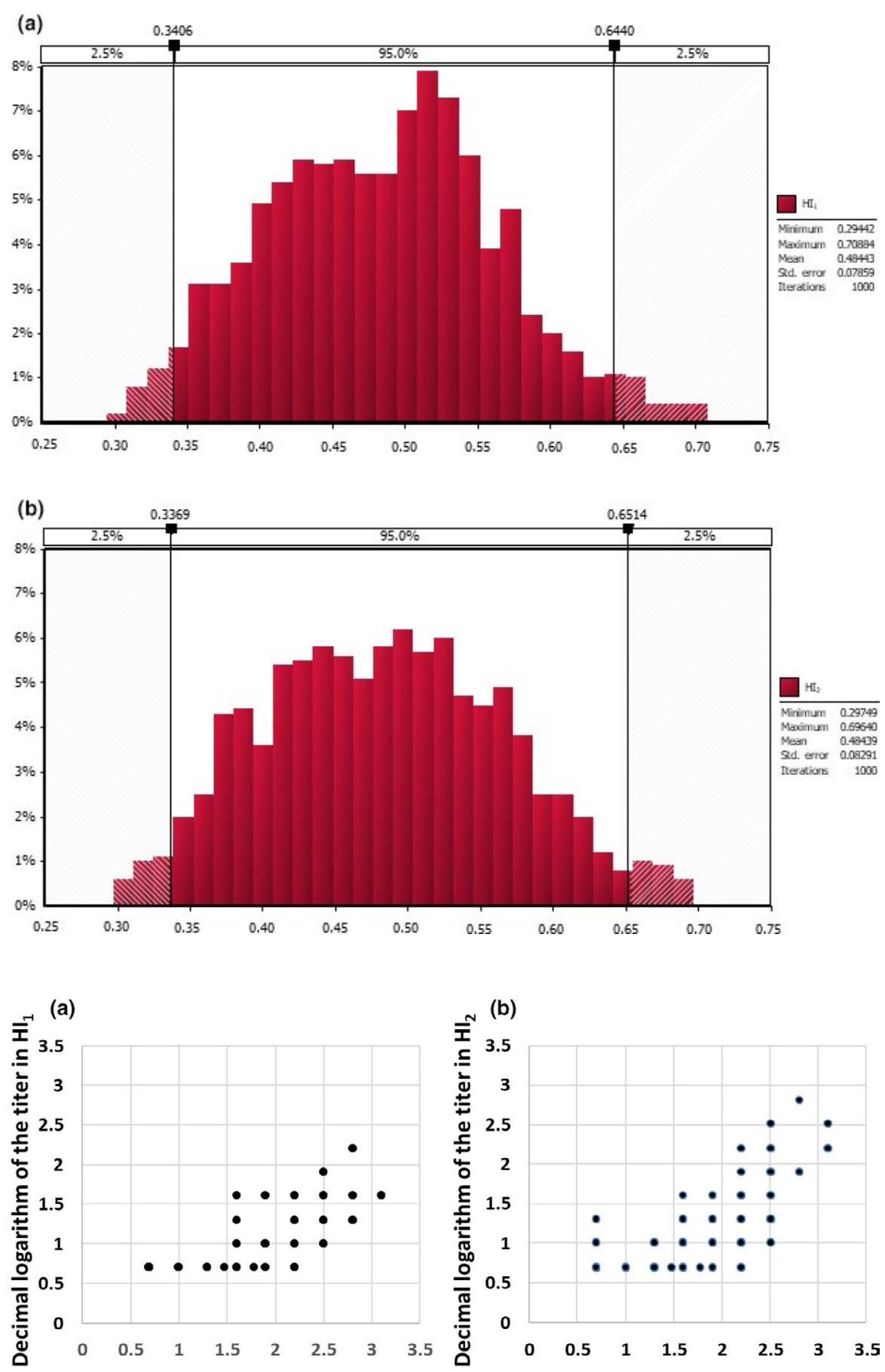

Logarithm of the titer in VNT

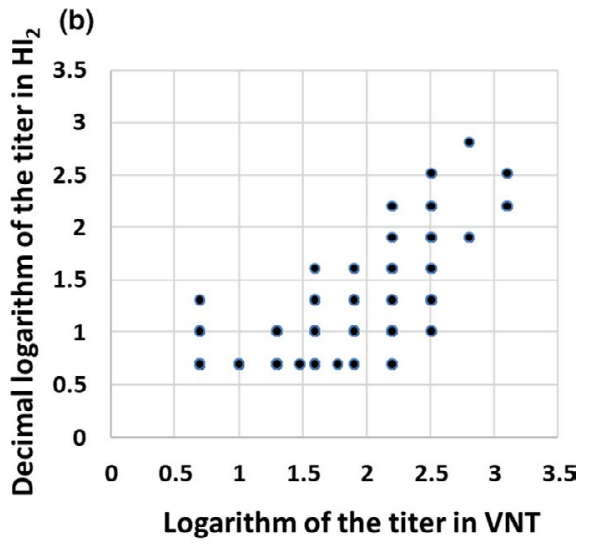

FIGURE 2 Stochastic estimation of the true prevalence based on hemagglutination inhibition assays $\left([\mathrm{a}]=\mathrm{HI}_{1}\right.$; [b] $\left.=\mathrm{HI}_{2}\right)(1,000$ iterations $)$
FIGURE 3 Correlation between hemagglutination inhibition assays $\left([\mathrm{a}]=\mathrm{HI}_{1} ;[\mathrm{b}]=\mathrm{HI}_{2}\right)$ and the virus micro-neutralization for the detection of antibodies directed against influenza $D$ virus characteristics of the two $\mathrm{HI}$ assays. Indeed, the same formal cut-off can be proposed for both tests. The antigenic differences between the two viruses therefore do not alter the degree of detection of anti-IDV antibodies in this cohort of Moroccan cattle sera. However, similar studies regarding other species are needed.

Until currently, the establishment of cut-off of $\mathrm{HI}$ assays was not formalized for the detection of antibodies directed to IDV. Previous studies have used titres of $10-40$ as thresholds for IDV positive antibody titres (Luo et al., 2017; Salem et al., 2017). This establishment is of prime importance to assess the diagnostic sensitivity and specificity of $\mathrm{HI}$ assays, to compare seroprevalence studies (and thus geographical areas) and to calculate the true prevalence of IDV. In addition, the recent development of monoclonal-based competitive ELISA used $\mathrm{HI}$ as reference test (Moreno et al., 2019) and emphasizes the importance of the establishment of a formal cut-off for any $\mathrm{HI}$ assay.

Among the mitigation measure against IDV, the vaccination is a credible option (e.g. Wan et al., 2018), especially in its main host, i.e. cattle (Dane et al., 2019; Salem et al., 2019). The choice of any strategy is based on the estimation of the cost-benefit ratio (e.g. Renault et al., 2019; Souley Kouato et al., 2018). Indeed, to be able 
to quantify the cost (in monetary terms), one needs the estimation of the true prevalence of IDV. For the development of future ELISA tests (i.e. screening tools for the detection of antibodies against IDV), a validation with at least an $\mathrm{HI}$ assay (e.g. Moreno et al., 2019) followed by inference of VNT using the methodology developed in this study or by the direct use of VNT as reference test is recommended.

One limitation of this study is the absence of complete sampling design, which needs a good knowledge of the sampling frame. However, sera of this study were sampled in numerous regions of Morocco to give a good representability of the cattle population.

The present study and methodology should be extended to samples from other continents (and/or other circulating strains of IDV) and other species in the purpose to consolidate the formal positivity cut-off of $\mathrm{HI}$ assays proposed here.

\section{5 | CONCLUSION}

This study allowed to formally establishing the positivity cut-off of the $\mathrm{HI}$ assays for the detection of antibodies directed against IDV. This information is of prime importance to estimate the diagnostic sensitivity and specificity of the test relatively to the VNT, which is the reference test. Using these characteristics, the true prevalence of IDV should be determined in a country.

\section{ACKNOWLEDGEMENTS}

This study was performed under the Grant Agreement Number GP/ EFSA/AFSCO/2017/01 - GA04, entitled 'Risk assessment for influenza D in Europe'. The article reflects only the author's view, and the EFSA Authority is not responsible for any use that may be made of the information it contains. The authors thank Salem and collaborators for the sharing of a subset of raw data from a previous study (Salem et al., 2017).

\section{CONFLICT OF INTERESTS}

The authors declare that they have no competing interests.

\section{ETHICAL APPROVAL}

Ethical statement is not applicable to this study as the raw data were gathered through part of the study form Salem et al. (2017) without any additional animal experimentation.

\section{DATA AVAILABILITY STATEMENT}

The data that support the findings of this study are available from the corresponding author upon request.

\section{ORCID}

Claude Saegerman iD https://orcid.org/0000-0001-9087-7436 Mariette F. Ducatez iD https://orcid.org/0000-0001-9632-5499

\section{REFERENCES}

Asha, K., \& Kumar, B. (2019). Emerging influenza D virus threat: What we know so far! Journal of Clinical Medicine, 8(2), E192. https://doi. org/10.3390/jcm8020192
Borkenhagen, L. K., Mallinson, K. A., Tsao, R. W., Ha, S. J., Lim, W. H., Toh, T. H., ... Gray, G. C. (2018). Surveillance for respiratory and diarrheal pathogens at the human-pig interface in Sarawak, Malaysia. PLoS One, 13(7), e0201295. https://doi.org/10.1371/journal.pone.0201295

Chiapponi, C., Faccini, S., Fusaro, A., Moreno, A., Prosperi, A., Merenda, M., ... Foni, E. (2019). Detection of a new genetic cluster of influenza D virus in Italian cattle. Viruses, 11(12), E1110. https://doi. org/10.3390/v11121110

Cicchetti, D., \& Feinstein, A. (1990). High agreement but low kappa: II. Resolving the paradoxes. Journal of Clinical Epidemiology, 43, 551558. https://doi.org/10.1016/0895-4356(90)90159-m

Dane, H., Duffy, C., Guelbenzu, M., Hause, B., Fee, S., Forster, F., ... Lemon, K. (2019). Detection of influenza D virus in bovine respiratory disease samples, UK. Transboundary and Emerging Diseases, 66(5), 2184-2187. https://doi.org/10.1111/tbed.13273

Faccini, S., De Mattia, A., Chiapponi, C., Barbieri, I., Boniotti, M. B., Rosignoli, C., ... Nigrelli, A. D. (2017). Development and evaluation of a new Real-Time RT-PCR assay for detection of proposed influenza D virus. Journal of Virological Methods, 243, 31-34. https://doi. org/10.1016/j.jviromet.2017.01.019

Ferguson, L., Eckard, L., Epperson, W. B., Long, L. P., Smith, D., Huston, C., ... Wan, X. F. (2015). Influenza D virus infection in Mississippi beef cattle. Virology, 486, 28-34. https://doi.org/10.1016/j. virol.2015.08.030

Ferguson, L., Olivier, A.K., Genova, S., Epperson, W.B., Smith, D.R., Schneider, L., ... Wan, X.-F. (2016). Pathogenesis of influenza D virus in cattle. Journal of Virology, 90, 5636-5642. htpps://doi. org/10.1128/JVI.03122-15

Flynn, O., Gallagher, C., Mooney, J., Irvine, C., Ducatez, M., Hause, B., ... Ryan, E. (2018). Influenza D virus in cattle, Ireland. Emerging Infectious Diseases, 24(2), 389-391. https://doi.org/10.3201/eid2402.170759

Gauger, P. C., \& Vincent, A. L. (2020). Serum virus neutralization assay for detection and quantitation of serum neutralizing antibodies to influenza A virus in swine. Methods in Molecular Biology, 2123, 321-333. https://doi.org/10.1007/978-1-0716-0346-8_23

Hause, B. M., Collin, E. A., Liu, R., Huang, B., Sheng, Z., Lu, W., ... Li, F. (2014). Characterization of a novel influenza virus in cattle and swine: Proposal for a new genus in the orthomyxoviridae family. MBio, 5(2), e00031-14. https://doi.org/10.1128/mBio.00031-14

Hause, B. M., Ducatez, M., Collin, E. A., Ran, Z., Liu, R., Sheng, Z., ... Li, F. (2013). Isolation of a novel swine influenza virus from Oklahoma in 2011 which is distantly related to human influenza C viruses. PLoS Path, 9(2), e1003176. https://doi.org/10.1371/journal.ppat.1003176

Hause, B. M., Huntimer, L., Falkenberg, S., Henningson, J., Lechtenberg, K., \& Halbur, T. (2017). An inactivated influenza D virus vaccine partially protects cattle from respiratory disease caused by homologous challenge. Veterinary Microbiology, 199, 47-53. https://doi. org/10.1016/j.vetmic.2016.12.024

Holwerda, M., Kelly, J., Laloli, L., Stürmer, I., Portmann, J., Stalder, H., \& Dijkman, R. (2019). Determining the replication kinetics and cellular tropism of influenza D virus on primary well-differentiated human airway epithelial cells. Viruses, 11(4), E377. https://doi.org/10.3390/ v11040377

Kesinger, E., Liu, J., Jensen, A., Chia, C. P., Demers, A., \& Moriyama, H. (2018). Influenza D virus M2 protein exhibits ion channel activity in Xenopus laevis oocytes. PLoS One, 13(6), e0199227. https://doi. org/10.1371/journal.pone.0199227

Luo, J., Ferguson, L., Smith, D. R., Woolums, A. R., Epperson, W. B., \& Wan, X. F. (2017). Serological evidence for high prevalence of Influenza D Viruses in Cattle, Nebraska, United States, 2003-2004. Virology, 501, 88-91. https://doi.org/10.1016/j.virol.2016.11.004

Moreno, A., Lelli, D., Lavazza, A., Sozzi, E., Zanni, I., Chiapponi, C., ... Brocchi, E. (2019). MAb-based competitive ELISA for the detection of antibodies against influenza D virus. Transboundary and Emerging Diseases, 66(1), 268-276. https://doi.org/10.1111/tbed.13012 
Murakami, S., Odagiri, T., Melaku, S. K., Bazartseren, B., Ishida, H., Takenaka-Uema, A., ... Horimoto, T. (2019). Influenza D virus infection in dromedary camels, Ethiopia. Emerging Infectious Diseases, 25(6), 1224-1226. https://doi.org/10.3201/eid2506.181158

O'Donovan, T., Donohoe, L., Ducatez, M. F., Meyer, G., \& Ryan, E. (2019). Seroprevalence of influenza $D$ virus in selected sample groups of Irish cattle, sheep and pigs. Irish Veterinary Journal, 72, 11. https:// doi.org/10.1186/s13620-019-0150-8

Oliva, J., Eichenbaum, A., Belin, J., Gaudino, M., Guillotin, J., Alzieu, J. P., ... Ducatez, M. F. (2019). Serological evidence of influenza D virus circulation among cattle and small ruminants in France. Viruses, 11(6), E516. https://doi.org/10.3390/v11060516

Oliva, J., Mettier, J., Sedano, L., Delverdier, M., Bourgès-Abella, N., Hause, B., ...Ducatez, M. F. (2019). A murine model for the study of influenza D virus. Journal of Virology, 94(4), JVI.01662-19. https://doi. org/10.1128/JVI.01662-19

Oliva, J., Salem, E., Meyer, G., \& Ducatez, M. (2018). Le virus influenza D: Un nouvel agent du complexe respiratoire bovin?Le Point Vétérinaire, $135,52-55$

Petrie, A., \& Watson, P. (2013). Statistics for veterinary and animal science (3rd ed., p. 408). Wiley-Blackwell. ISBN: 978-0-470-67075-0.

Renault, V., Hambe, H. A., Van Vlaenderen, G., Timmermans, E., Mohamed, A. M., Ethgen, O., \& Saegerman, C. (2019). Economic impact of contagious caprine pleuropneumonia and cost-benefit analysis of the vaccination programmes based on a one-year continuous monitoring of flocks in the arid and semi-arid lands of Kenya. Transbound Emerg Dis., 66(6), 2523-2536. https://doi.org/10.1111/ tbed.13317

Rogan, W. J., \& Gladen, B. (1978). Estimating prevalence from the results of a screening test. American Journal of Epidemiology, 107(1), 71-76. https://doi.org/10.1093/oxfordjournals.aje.a112510

Salem, E., Cook, E. A. J., Lbacha, H. A., Oliva, J., Awoume, F., Aplogan, G. L., ... Ducatez, M. F. (2017). Serologic evidence for influenza C and D virus among ruminants and camelids, Africa, 1991-2015. Emerging Infectious Diseases, 23(9), 1556-1559. https://doi.org/10.3201/eid23 09.170342

Salem, E., Hägglund, S., Cassard, H., Corre, T., Näslund, K., Foret, C., ... Meyer, G. (2019). Pathogenesis, host innate immune response, and aerosol transmission of influenza $D$ virus in cattle. Journal of Virology, 93(7), e01853-18. https://doi.org/10.1128/JVI.01853-18

Silveira, S., Falkenberg, S. M., Kaplan, B. S., Crossley, B., Ridpath, J. F., Bauermann, F. B., ... Neill, J. D. (2019). Serosurvey for influenza D virus exposure in cattle, United States, 2014-2015. Emerging Infectious Diseases, 25(11), 2074-2080. https://doi.org/10.3201/ eid2511.190253

Snoeck, C. J., Oliva, J., Pauly, M., Losch, S., Wildschutz, F., Muller, C. P., ... Ducatez, M. F. (2018). Influenza D virus circulation in cattle and swine, Luxembourg, 2012-2016. Emerging Infectious Diseases, 24(7), 1388-1389. https://doi.org/10.3201/eid2407.171937

Souley Kouato, B., Thys, E., Renault, V., Abatih, E., Marichatou, H., Issa, S., \& Saegerman, C. (2018). Spatio-temporal patterns of foot-andmouth disease transmission in cattle between 2007 and 2015 and quantitative assessment of the economic impact of the disease in Niger. Transboundary and Emerging Diseases, 65(4), 1049-1066. https://doi.org/10.1111/tbed.12845

Trombetta, C. M., Marchi, S., Manini, I., Kistner, O., Li, F., Piu, P., ... Montomoli, E. (2019). Influenza D virus: serological evidence in the Italian population from 2005 to 2017. Viruses, 12(1), E30. https://doi. org/10.3390/v12010030

Truelove, S., Zhu, H., Lessler, J., Riley, S., Read, J. M., Wang, S., ... Cummings, D. A. T. (2016). A comparison of hemagglutination inhibition and neutralization assays for characterizing immunity to seasonal influenza A. Influenza and Other Respiratory Viruses, 10(6), 518-524. https://doi.org/10.1111/irv.12408

Wan, Y., Kang, G., Sreenivasan, C., Daharsh, L., Zhang, J., Fan, W., ... Li, Q. (2018). A DNA vaccine expressing consensus hemagglutinin-esterase fusion protein protected guinea pigs from infection by two lineages of influenza D virus. Journal of Virology, 92(11), e00110-18. https://doi.org/10.1128/JVI.00110-18

White, S. K., Ma, W., McDaniel, C. J., Gray, G. C., \& Lednicky, J. A. (2016). Serologic evidence of exposure to influenza $D$ virus among persons with occupational contact with cattle. Journal of Clinical Virology, 81, 31-33. https://doi.org/10.1016/j.jcv.2016.05.017

Yu, J., Hika, B., Liu, R., Sheng, Z., Hause, B. M., Li, F., \& Wang, D. (2017). The hemagglutinin-esterase fusion glycoprotein is a primary determinant of the exceptional thermal and acid stability of influenza $D$ virus. mSphere, 2(4), e00254-17. https://doi.org/10.1128/mSphe re.00254-17

Zhang, M., Hill, J. E., Godson, D. L., Ngeleka, M., Fernando, C., \& Huang, Y. (2019). The pulmonary virome, bacteriological and histopathological findings in bovine respiratory disease from western Canada. Transboundary and Emerging Diseases, 67(2), 924-934. https://doi. org/10.1111/tbed.13419

Zhang, X., Outlaw, C., Olivier, A. K., Woolums, A., Epperson, W., \& Wan, $X$. F. (2019). Pathogenesis of co-infections of influenza $D$ virus and Mannheimia haemolytica in cattle. Veterinary Microbiology, 231, 246253. https://doi.org/10.1016/j.vetmic.2019.03.027

\section{SUPPORTING INFORMATION}

Additional supporting information may be found online in the Supporting Information section.

How to cite this article: Saegerman C, Salem E, Ait Lbacha H, et al. Formal estimation of the seropositivity cut-off of the hemagglutination inhibition assay in field diagnosis of influenza $D$ virus in cattle and estimation of the associated true prevalence in Morocco. Transbound Emerg Dis. 2020;00:1-8. https://doi.org/10.1111/tbed.13805 